\title{
Comparison of liver function after laparoscopically assisted and open distal gastrectomies for patients with liver disease
}

\author{
Hong Man Yoon $\cdot$ Han-Kwang Yang $\cdot$ \\ Hyuk-Joon Lee · Do Joong Park • Hyung-Ho Kim • \\ Kuhn-Uk Lee $\cdot$ Hye Seong Ahn · Jae-Jin Jo
}

Received: 30 December 2009/Accepted: 1 November 2010/Published online: 18 March 2011

(C) The Author(s) 2011. This article is published with open access at Springerlink.com

\begin{abstract}
Background Several studies have suggested that carbon dioxide $\left(\mathrm{CO}_{2}\right)$ pneumoperitoneum may have an effect on liver function. This study aimed to compare liver function after laparoscopically assisted distal gastrectomy (LADG) and open distal gastrectomy (ODG) for patients with liver disease.

Methods Between January 2006 and December 2007, the study enrolled 50 patients with EGC and liver disease including 18 liver cirrhosis patients, 3 fatty liver patients ( $n=3$ ), and 29 healthy hepatitis $\mathrm{B}$ or $\mathrm{C}$ virus carriers. Albumin, total bilirubin, alkaline phosphatase, aspartate aminotransferase, and alanine aminotransferase levels as well as the volume of drainage in the LADG $(n=18)$ and ODG ( $n=32$ ) groups were determined to assess liver function.

Results The albumin level on postoperative day 7 was significantly higher in the LADG group $(3.5 \mathrm{mg} / \mathrm{dl})$ than in the ODG group $(3.1 \mathrm{mg} / \mathrm{dl} ; p=0.042)$, and the volume of drainage on postoperative day 2 was significantly lower in
\end{abstract}

H. M. Yoon · D. J. Park · H.-H. Kim · K.-U. Lee .

H. S. Ahn · J.-J. Jo

Department of Surgery, Seoul National University College of Medicine, Seoul, Korea

H.-K. Yang $(\varangle) \cdot$ H.-J. Lee

Department of Surgery and Cancer Research Institute, Seoul National University Hospital, Seoul National University College of Medicine, 411-764 101 Daehak-ro Jongro-gu, Seoul, Korea e-mail: hkyang@snu.ac.kr

H. M. Yoon

Gastric Cancer Branch, National Cancer Center, Goyang-si, Korea the LADG group $(154.3 \mathrm{ml})$ than in the ODG group (403.1 ml; $p=0.013$ ). Diuretics were needed by three patients $(16.7 \%)$ in the LADG group and six patients $(18.7 \%)$ in the ODG group for control of ascites $(p=0.587)$. For the patients with liver cirrhosis, none of the parameters between the two groups were significantly different.

Conclusion For gastric cancer patients with chronic liver disease, LADG can be considered a safe surgical procedure showing surgical outcomes comparable with those for ODG.

Keywords Gastric cancer - LADG - Liver disease

The proportion of early gastric cancer (EGC) cases has increased recently, and the treatment of EGC has expanded to include laparoscopically assisted distal gastrectomy (LADG). During laparoscopic procedures, a carbon dioxide $\left(\mathrm{CO}_{2}\right)$ pneumoperitoneum is established. In cirrhotic rats, $\mathrm{CO}_{2}$ pneumoperitoneum markedly decreases the total hepatic blood flow by mechanical compression or hypercapnia-induced vasoconstriction [1]. $\mathrm{A} \mathrm{CO}_{2}$ pneumoperitoneum of 4 or $8 \mathrm{mmHg}$ decreases the sinusoidal perfusion rate and increases sinusoidal leukostasis and venular leukocyte adherence in a rat model [2].

It was thought that $\mathrm{CO}_{2}$ pneumoperitoneum had a deleterious effect on postoperative liver function. Patients with liver disease sometimes experience uncontrolled postoperative ascites. Therefore, many surgeons hesitate to perform a laparoscopic operation using $\mathrm{CO}_{2}$ pneumoperitoneum, especially for patients with liver cirrhosis.

This study compared liver function after LADG and open distal gastrectomy (ODG) for patients with EGC and liver disease. 


\section{Materials and methods}

We retrospectively reviewed 1,604 patients who underwent surgery for EGC between January 2006 and December 2007 at Seoul National University Hospital and Seoul National University Bundang Hospital. The study enrolled 51 patients who had liver disease and underwent distal gastrectomy by LADG or ODG with more than D1 + a lymphadenectomy for EGC.

The diagnoses for the patients were determined by endoscopy, endoscopic ultrasound, and computed tomography (CT). One patient was excluded from the study because he underwent gastrectomy and distal pancreatectomy.

The study included liver cirrhosis patients, fatty liver patients, healthy hepatitis B virus (HBV) carriers, and healthy hepatitis $\mathrm{C}$ virus (HCV) carriers. Liver cirrhosis was classified by the Child-Pugh classification. The Child-Pugh scores were calculated according to the degrees of hepatic encephalopathy, ascites, total bilirubin level, serum albumin level, and prothrombin time or international normalized ratio (INR). With the Child-Pugh classification, total scores are classified as 5 to 6 (grade A), 7 to 9 (grade B), and 10 to 15 (grade $\mathrm{C}$ ). A healthy $\mathrm{HBV}$ or $\mathrm{HCV}$ carrier was defined as a patient without cirrhosis who had hepatitis B surface antigen (HBsAg) or anti-HCV as diagnosed by a blood sample test. Fatty liver was preoperatively diagnosed by CT.

During laparoscopy, the $\mathrm{CO}_{2}$ pressure was kept at $12 \mathrm{mmHg}$. Data were collected from medical charts, operative records, and pathology reports. We measured the volume of drainage and laboratory data including albumin, aspartate aminotransferase (AST), alanine aminotransferase (ALT), alkaline phosphatase (ALP), and total bilirubin (TB). Blood samples were collected before surgery and on postoperative days 2,5 , and 7 .

In the current study, one Jackson-Pratt closed suction drain $(200 \mathrm{ml})$ was placed routinely in the right subhepatic area just before closure, and the volume of drainage through the closed suction drain was checked daily. Removal of the drain was performed when the daily drainage amount was less than $200 \mathrm{ml}$. We compared the LADG group with the ODG group using the chi-square test and the Mann-Whitney $U$ test.

\section{Results}

In this study of patients with liver disease, 18 patients underwent LADG and 32 patients underwent ODG. Table 1 shows the patient demographic and clinicopathologic factors in relation to the type of surgery. There were no significant differences between the LADG and ODG groups in terms of age, gender, operative time, or number of resected lymph nodes. There were no perioperative mortalities, and 10 cases of perioperative complications occurred.

In the LADG group, two patients had uncontrolled ascites, and one patient had reoperations because of abdominal bleeding. In the ODG group, four patients had uncontrolled ascites, two patients had paralytic ileus, and one patient had pneumonia.
Table 1 Patient demographic and clinicopathologic factors

$H B s A G$ hepatitis B surface antigen, $L A D G$ laparoscopically assisted distal gastrectomy, $O D G$ open distal gastrectomy

\begin{tabular}{llll}
\hline & LADG & ODG & $p$ Value \\
\hline Age (years) & $56.7 \pm 8.5$ & $57.4 \pm 10.7$ & 0.34 \\
Gender (M:F) & $13: 5$ & $28: 4$ & 0.07 \\
Operative time (min) & $223.6 \pm 54.4$ & $192.5 \pm 63.2$ & 0.21 \\
Resected lymph nodes & $38.0 \pm 22.9$ & $36.1 \pm 19.4$ & 0.51 \\
Liver disease & & & 0.59 \\
Liver cirrhosis (child class A or B) & $7(6 / 1)$ & $11(10 / 1)$ & \\
HBsAg(+) & 8 & 19 & \\
Anti-HCV(+) & 1 & 1 & \\
Fatty liver & 2 & 1 & \\
LN dissection & & & \\
D1 & 0 & 0 & \\
D1 + a & 3 & 3 & 0.57 \\
D1 + b & 6 & 4 & \\
D2 & 9 & 25 & \\
Complication & & & \\
Abdominal bleeding & 1 & 0 & \\
Uncontrolled ascites & 2 & 2 & \\
Paralytic ileus & 0 & 1 & \\
Pneumonia & 0 & & \\
\hline
\end{tabular}


With respect to liver function parameters, neither the AST, ALT, and TB levels nor the volume of drainage on postoperative days 2,5 , and 7 differed significantly between the two groups (Table 2). The albumin level on postoperative day 7 was significantly higher $(p=0.042$; Fig. 1) and the volume of drainage on postoperative day 2 significantly lower ( $p=0.013$; Fig. 2$)$ in the LADG group than the ODG group. Three patients $(16.7 \%)$ in the LADG group and six patients (18.7\%) in the ODG group needed diuretics to control the volume of drainage.

Among the patients with liver cirrhosis, the albumin level on postoperative day 7 was lower than in the ODG group ( $p=0.049$; Fig. 3 ). The other parameters did not differ significantly between the LADG and ODG groups (Table 3).

Table 2 Liver function parameters

\begin{tabular}{|c|c|c|c|}
\hline & LADG & ODG & $p$ Value \\
\hline \multicolumn{4}{|l|}{ AST (IU/L) } \\
\hline Preoperative day & $33.8 \pm 14.4$ & $36.3 \pm 18.3$ & 0.754 \\
\hline POD 2 & $39.7 \pm 17.5$ & $50.8 \pm 36.7$ & 0.281 \\
\hline POD 5 & $29.5 \pm 9.9$ & $34.7 \pm 13.9$ & 0.228 \\
\hline POD 7 & $33.1 \pm 12.6$ & $31.9 \pm 14.7$ & 0.531 \\
\hline \multicolumn{4}{|l|}{ ALT (IU/L) } \\
\hline Preoperative day & $38.4 \pm 21.5$ & $39.1 \pm 33.4$ & 0.462 \\
\hline POD 2 & $39.7 \pm 17.6$ & $39.6 \pm 29.3$ & 0.364 \\
\hline POD 5 & $27.9 \pm 12.3$ & $32.4 \pm 19.2$ & 0.581 \\
\hline POD 7 & $29.0 \pm 16.1$ & $30.3 \pm 19.5$ & 0.943 \\
\hline \multicolumn{4}{|l|}{ TB (mg/dL) } \\
\hline Preoperative day & $0.91 \pm 0.31$ & $0.90 \pm 0.30$ & 0.977 \\
\hline POD 2 & $1.23 \pm 0.45$ & $1.31 \pm 0.53$ & 0.814 \\
\hline POD 5 & $1.37 \pm 0.68$ & $1.55 \pm 1.24$ & 0.821 \\
\hline POD 7 & $1.31 \pm 0.69$ & $1.31 \pm 1.03$ & 0.420 \\
\hline \multicolumn{4}{|l|}{ Alb (g/dL) } \\
\hline Preoperative day & $4.11 \pm 0.57$ & $4.01 \pm 0.37$ & 0.283 \\
\hline POD 2 & $3.39 \pm 0.38$ & $3.17 \pm 0.28$ & 0.059 \\
\hline POD 5 & $3.36 \pm 0.44$ & $3.32 \pm 0.35$ & 0.561 \\
\hline POD 7 & $3.45 \pm 0.31$ & $3.14 \pm 0.20$ & $0.042 *$ \\
\hline \multicolumn{4}{|l|}{ ALP (IU/L) } \\
\hline Preoperative day & $72.0 \pm 19.19$ & $79.0 \pm 23.9$ & 0.521 \\
\hline POD 2 & $60.4 \pm 22.3$ & $53.7 \pm 11.6$ & 0.403 \\
\hline POD 5 & $61.5 \pm 23.1$ & $58.1 \pm 16.7$ & 0.649 \\
\hline POD 7 & $68.9 \pm 28.3$ & $62.2 \pm 19.3$ & 0.761 \\
\hline \multicolumn{4}{|c|}{ Volume of drainage $(\mathrm{mL})$} \\
\hline POD 2 & $148.3 \pm 143.6$ & $382.6 \pm 539.0$ & $0.013^{*}$ \\
\hline POD 5 & $425.3 \pm 541.5$ & $601.0 \pm 762.5$ & 0.391 \\
\hline POD 7 & $584.3 \pm 482.8$ & $538.4 \pm 868.2$ & 0.448 \\
\hline
\end{tabular}

$L A D G$ laparoscopically assisted distal gastrectomy, $O D G$ open distal gastrectomy, $A S T$ aspartate aminotransferase, $P O D$ postoperative day $A L T$ alanine aminotransferase, $T B$ total bilirubin, $A l b$ albumin, $A L P$ alkaline phosphatase

$* p<0.05$

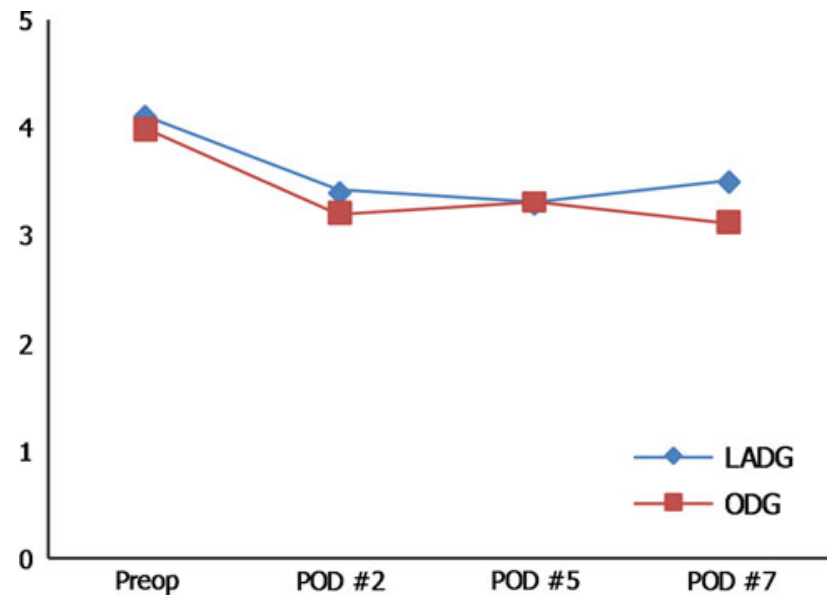

Fig. 1 Albumin is higher in laparoscopically assisted distal gastrectomy (LADG) and especially significant on postoperative day (POD) $7(p=0.042)$

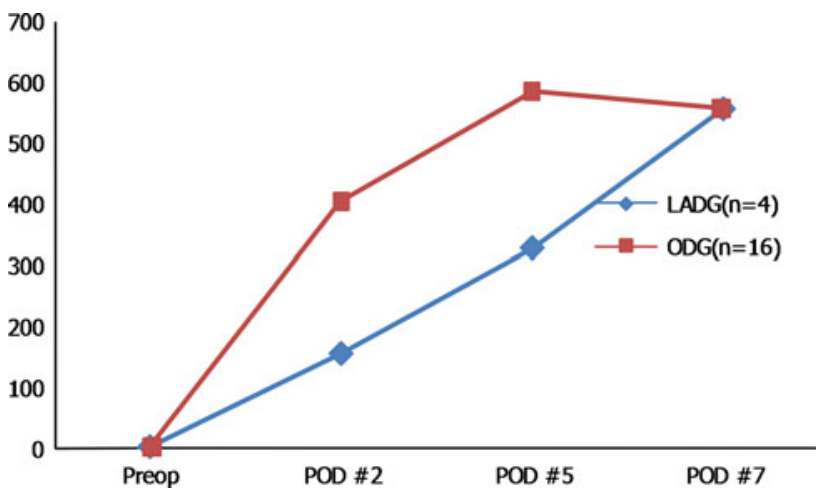

Fig. 2 The volume of drainage is lower in laparoscopically assisted distal gastrectomy (LADG) and especially significant on postoperative day (POD) $2(p=0.013)$

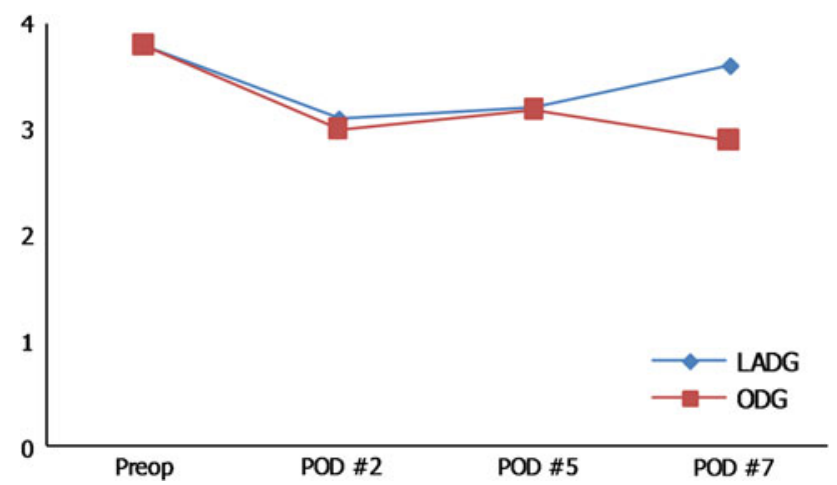

Fig. 3 Albumin is higher in laparoscopically assisted distal gastrectomy (LADG) and especially significant on postoperative day (POD) $7(p=0.049)$

\section{Discussion}

This retrospective study compared liver function between LADG and ODG for patients with EGC and liver disease. 
Table 3 Liver function parameters in patients with liver cirrhosis
$L A D G$ laparoscopically assisted distal gastrectomy, $O D G$ open distal gastrectomy, $A S T$ aspartate aminotransferase, $P O D$ postoperative day $A L T$ alanine aminotransferase, $T B$ total bilirubin, $A l b$ albumin, $A L P$ alkaline phosphatase $* p<0.05$

\begin{tabular}{|c|c|c|c|}
\hline & LADG & ODG & $p$ Value \\
\hline \multicolumn{4}{|l|}{ AST (IU/L) } \\
\hline Preoperative day & $42.0 \pm 16.6$ & $46.7 \pm 17.7$ & 0.602 \\
\hline POD 2 & $54.9 \pm 17.7$ & $47.7 \pm 19.8$ & 0.383 \\
\hline POD 5 & $37.6 \pm 10.3$ & $42.7 \pm 19.8$ & 0.785 \\
\hline POD 7 & $39.4 \pm 13.0$ & $40.4 \pm 17.3$ & 0.906 \\
\hline \multicolumn{4}{|l|}{ ALT (IU/L) } \\
\hline Preoperative day & $48.7 \pm 27.1$ & $40.9 \pm 28.4$ & 0.292 \\
\hline POD 2 & $48.0 \pm 19.4$ & $32.5 \pm 15.2$ & 0.091 \\
\hline POD 5 & $33.4 \pm 15.2$ & $29.5 \pm 12.7$ & 0.858 \\
\hline POD 7 & $35.0 \pm 16.6$ & $29.6 \pm 14.9$ & 0.513 \\
\hline \multicolumn{4}{|l|}{$\mathrm{TB}(\mathrm{mg} / \mathrm{dL})$} \\
\hline Preoperative day & $0.79 \pm 0.25$ & $0.97 \pm 0.35$ & 0.241 \\
\hline POD 2 & $1.03 \pm 0.40$ & $1.43 \pm 0.42$ & 0.088 \\
\hline POD 5 & $1.27 \pm 0.26$ & $2.29 \pm 1.73$ & 0.153 \\
\hline POD 7 & $1.28 \pm 0.08$ & $1.91 \pm 1.50$ & $>0.999$ \\
\hline \multicolumn{4}{|l|}{$\mathrm{Alb}(\mathrm{g} / \mathrm{dL})$} \\
\hline Preoperative day & $3.77 \pm 0.60$ & $3.81 \pm 0.46$ & 0.862 \\
\hline POD 2 & $3.13 \pm 0.21$ & $3.04 \pm 0.39$ & 0.661 \\
\hline POD 5 & $3.17 \pm 0.39$ & $3.21 \pm 0.37$ & 0.855 \\
\hline POD 7 & $3.64 \pm 0.41$ & $2.86 \pm 0.34$ & $0.049 *$ \\
\hline \multicolumn{4}{|l|}{ ALP (IU/L) } \\
\hline Preoperative day & $75.0 \pm 16.3$ & $87.1 \pm 26.4$ & 0.431 \\
\hline POD 2 & $67.9 \pm 31.5$ & $55.2 \pm 11.2$ & 0.434 \\
\hline POD 5 & $67.6 \pm 31.4$ & $58.7 \pm 17.7$ & 0.656 \\
\hline POD 7 & $70.8 \pm 29.8$ & $56.3 \pm 16.0$ & 0.323 \\
\hline \multicolumn{4}{|c|}{ Volume of drainage $(\mathrm{mL})$} \\
\hline POD 2 & $167.9 \pm 76.0$ & $627.9 \pm 787.4$ & 0.071 \\
\hline POD 5 & $622.3 \pm 601.6$ & $904.3 \pm 995.0$ & 0.882 \\
\hline POD 7 & $715.0 \pm 15.0$ & $1184.4 \pm 1287.6$ & $>0.999$ \\
\hline
\end{tabular}

Normal portal venous pressure is 7 to $10 \mathrm{mmHg}$, and about one-half of the hepatic blood flow is derived from the portal venous system. The healthy liver receives about $25 \%$ of its blood supply via the hepatic artery and the remainder through the portal vein.

In laparoscopic surgery, a $\mathrm{CO}_{2}$ pneumoperitoneum (12-14 $\mathrm{mmHg}$ ) is required for optimal visualization of the operative field. Sala-Blanch et al. [3] showed that hepatic blood flow was significantly lower than at baseline with both helium (He) $(63 \% ; p<0.001)$ and $\mathrm{CO}_{2}(24 \%$; $p<0.05)$ pneumoperitoneum $90 \mathrm{~min}$ after insufflation. Etoh et al. [4] reported that decreased portal blood flow under a $\mathrm{CO}_{2}$ pneumoperitoneum is the most likely reason for transient liver dysfunction after LADG.

Elevated serum transaminase levels within 3 days after surgery and decreased serum albumin levels recovered more rapidly after LADG than after ODG [4]. Guven and Oral. [5] reported that unexplained elevation of ALT was common after laparoscopic cholecystectomy and pneumoperitoneum and that the consequent intraabdominal hypertension-induced hepatic ischemia appeared to be the cause.

Such disturbances, however, were self-limited and not associated with any morbidity in the setting studied. Bickel et al. [6] showed that for 1,034 patients, induction of a $\mathrm{CO}_{2}$ pneumoperitoneum did not cause deranged liver function tests after laparoscopic cholecystectomy.

In the current study, all parameters of liver function except AST on day 7 and ALP on day 2 seemed better in the LADG group than in the ODG group, and among these parameters, albumin level on postoperative day 7 ( $p=0.042$; Fig. 1) and volume of drainage on postoperative day 2 ( $p=0.013$; Fig. 2 ) were significant. All the parameters except volume of drainage in both the LADG and ODG groups were within the normal range.

Concerning the low volume of drainage in the LADG group in the current study, $\mathrm{CO}_{2}$ pneumoperitoneum perhaps did not complicate the liver function, and LADG may 
have been less invasive than ODG from the viewpoint of less handling of tissue and bowel. A high volume of drainage may require diuretics and a salt-restricted diet for control of ascites, and discharge may be delayed.

In liver cirrhosis, because portal venous blood flow is reduced, the maintenance of hepatic arterial blood flow and the preserved hepatic arterial buffer response probably represents a beneficial mechanism for hepatic circulation [2]. Our study showed that in patients with liver cirrhosis, only the ALT level on postoperative day 2 was abnormal and higher in the LADG group, but the difference was not significant, and recovery was rapid. Because the portal vein pressure is 7 to $10 \mathrm{mmHg}$, a $\mathrm{CO}_{2}$ pneumoperitoneum mainly influences portal blood flow.

Postoperative ascites occurs more frequently in Child's class $\mathrm{B}$ and $\mathrm{C}$ patients $(63.6 \%)$ than in class A patients (13\%; $p=0.001)$ [7]. The hepatoduodenal ligament in patients with liver cirrhosis contains more lymphatic vessels than in patients with healthy livers [8].

Compared with ODG, LADG is minimally invasive. Our study showed that the volume of drainage was lower in the LADG group and that no significant difference existed in the number of resected lymph nodes. $\mathrm{A} \mathrm{CO}_{2}$ pneumoperitoneum did not seem to influence the amount of ascites.

In a prospective randomized trial, Hasukic [9] reported significantly decreased postoperative changes in liver function tests after laparoscopic cholecystectomy using lowpressure $(7 \mathrm{mmHg})$ instead of high-pressure $(14 \mathrm{mmHg})$ procedures. We performed LADG under a $12-\mathrm{mmHg}$ pneumoperitoneum. If performed under low pressure, LADG is a reasonable choice for the patient with liver cirrhosis.

\section{Conclusion}

For gastric cancer patients with chronic liver disease, LADG can be considered a safe surgical procedure with outcomes comparable with those for ODG.
Disclosures Hong Man Yoon, Han-Kwang Yang, Hyuk-Joon Lee, Do-Joong Park, Hyung-Ho Kim, Kuhn-Uk Lee, Hye Seong Ahn, and Jae-Jin Jo have no conflicts of interest or financial ties to disclose.

Open Access This article is distributed under the terms of the Creative Commons Attribution Noncommercial License which permits any noncommercial use, distribution, and reproduction in any medium, provided the original author(s) and source are credited.

\section{References}

1. Tsuboi S, Yoshida T, Bandoh T, Ninmiya K, Baatar D (2002) Effects of carbon dioxide pneumoperitoneum on hemodynamics in cirrhotic rats. Surg Endosc 16:1220-1225

2. Leister I, Schüler P, Vollmar B, Stojanovic T, Füzesi L, Becker H, Markus PM (2003) A peritoneal cavity chamber for intravital microscopy of the liver under conditions of pneumoperitoneum. Surg Endosc 17:939-942

3. Sala-Blanch X, Fontanals J, Martínez-Palli G, Taurá P, Delgado S, Bosch J, Lacy AM, Visa J (1998) Effects of carbon dioxide vs helium pneumoperitoneum on hepatic blood flow. Surg Endosc 12:1121-1125

4. Etoh T, Shiraishi N, Tajima M, Shiromizu A, Yasuda K, Inomata M, Kitano S (2007) Transient liver dysfunction after laparoscopic gastrectomy for gastric cancer patients. World J Surg 31: 11151120

5. Guven HE, Oral S (2007) Liver enzyme alterations after laparoscopic cholecystectomy. J Gastrointestin Liver Dis 16:391-394

6. Bickel A, Weiar A, Eitan A (2008) Evaluation of liver enzymes following elective laparoscopic cholecystectomy: are they really elevated? J Gastrointest Surg 12:1418-1421

7. Jang HJ, Song HH, Woo KH, Kim M, Kae SH, Lee J, Cho JW, Kang JH, Lee SI, Gong SJ, Lee JA, Zang DY (2008) Clinical outcomes of patients with liver cirrhosis who underwent curative surgery for gastric cancer: a retrospective multicenter study. Dig Dis Sci 8:399-404

8. Beggenstoss AH, Cain JC (1957) Further studies on the lymphatic vessels at the hilus of the liver in man: their relation to ascites. Proc Mayo Clin 32:615-626

9. Hasukic S (2005) Postoperative changes in liver function tests: randomized comparison of low- and high-pressure laparoscopic cholecystectomy. Surg Endosc 19:1451-1455 